OPEN ACCESS

Edited by:

Emi Takahashi,

Boston Children's Hospital, USA

Reviewed by:

Irini Skaliora,

Biomedical Research Foundation of

the Academy of Athens, Greece

Bashkim Kadriu,

National Institute of Mental Health

(NIH), USA

*Correspondence:

Yusuke Hatanaka

hatanaka@kuhp.kyoto-u.ac.jp Keiji Wada

wada@ncnp.go.jp

Specialty section

This article was submitted to Child and Adolescent Psychiatry,

a section of the journal

Frontiers in Neuroscience

Received: 01 December 2016

Accepted: 17 January 2017

Published: 06 February 2017

Citation:

Hatanaka Y, Kabuta T and Wada K

(2017) Disturbance in Maternal

Environment Leads to Abnormal Synaptic Instability during Neuronal

Circuitry Development.

Front. Neurosci. 11:35.

doi: 10.3389/fnins.2017.00035

\section{Disturbance in Maternal Environment Leads to Abnormal Synaptic Instability during Neuronal Circuitry Development}

\author{
Yusuke Hatanaka ${ }^{1,2 *}$, Tomohiro Kabuta ${ }^{1}$ and Keiji Wada ${ }^{1 *}$ \\ ${ }^{1}$ Department of Degenerative Neurological Diseases, National Institute of Neuroscience, National Center of Neurology and \\ Psychiatry, Tokyo, Japan, ${ }^{2}$ Department of Neurology, Graduate School of Medicine, Kyoto University, Kyoto, Japan
}

Adverse maternal environment during gestation and lactation can have negative effects on the developing brain that persist into adulthood and result in behavioral impairment. Recent studies of human and animal models suggest epidemiological and experimental association between disturbances in maternal environments during brain development and the occurrence of neuropsychiatric disorders, including autism spectrum disorder, attention deficit hyperactivity disorder, schizophrenia, anxiety, depression, and neurodegenerative diseases. In this review, we summarize recent advances in understanding the effects of maternal metabolic and hormonal abnormalities on the developing brain by focusing on the dynamics of dendritic spine, an excitatory postsynaptic structure. We discuss the abnormal instability of dendritic spines that is common to developmental disorders and neurological diseases. We also introduce our recent studies that demonstrate how maternal obesity and hyperandrogenism leads to abnormal development of neuronal circuitry and persistent synaptic instability, which results in the loss of synapses. The aim of this review is to highlight the links between abnormal maternal environment, behavioral impairment in offspring, and the dendiric spine pathology of neuropsychiatric disorders.

\footnotetext{
Keywords: dendritic spines, synaptic development, maternal obesity, maternal hyperandrogenism, neuropsychiatric disorders
}

\section{INTRODUCTION}

The maternal environment is inevitably an environmental factor that impacts brain development in most animals are born to a mother. Recent studies of human and animal models provide evidence that disturbances in the maternal environment during development are associated with many neuropsychiatric disorders, such as autism spectrum disorder (ASD) (Baron-Cohen et al., 2005; Patterson, 2011; Xu et al., 2013), attention deficit hyperactivity disorder (ADHD) (Ray et al., 2009), anxiety (Sullivan et al., 2010), depression (Rice et al., 2007), schizophrenia (Kawai et al., 2004), Alzheimer's disease (Lahiri et al., 2009), and Parkinson's disease (Barlow et al., 2007). In this mini-review, we focus on abnormal metabolic and hormonal conditions that affect mothers, and review the association between these maternal environments and offspring behavior. Because several neuropsychiatric disorders show large deficits in synaptic connectivity (Penzes et al., 2011), we later summarize the synaptic pathologies of developmental disorders and neurological diseases. 
We also introduce our recent studies that demonstrate how maternal high-fat diet (HFD) and hyperandrogenism duce abnormal development of neuronal circuitry in offspring, which results in the loss or excess of synapses in later life. Our studies link abnormal maternal environment-induced behavioral impairment in offspring with the dendritic spine pathology of neuropsychiatric disorders. Based on their shared synaptic pathology during the development of neuronal circuitry, we propose that many neuropsychiatric disorders have a common underlying deficit in synaptic development. Not only is this synaptic instability found in developmental disorders of the nervous system, it is also found in late-onset neurodegenerative diseases.

\section{MATERNAL ENVIRONMENT IS ASSOCIATED WITH NEUROPSYCHIATRIC DISORDERS}

\section{Maternal Obesity}

Obesity is a worldwide health problem and a major contributor to the increased incidence of coronary artery disease, hypertension, and Type-II diabetes (Kopelman, 2000). Due to factors listed, many women are obese or overweight by the time they reach childbearing age (Kanagalingam et al., 2005; Huda et al., 2010). Thus, maternal obesity can be a major contributor to the disturbance in brain development of the children during preand postnatal period. Epidemiological studies have shown that maternal obesity has adverse effects on brain development in children, which can result in ADHD (Rodriguez et al., 2008; Rodriguez, 2010), schizophrenia (Kawai et al., 2004), cognitive impairments (Van Lieshout et al., 2011), and eating disorders (Favaro et al., 2006; Allen et al., 2009). Maternal obesity also predisposes children to metabolic disorders (Deierlein et al., 2011), and is associated with depression (Rofey et al., 2009), anxiety disorder (Rofey et al., 2009), learning disability (Cserjési et al., 2007), ADHD (Waring and Lapane, 2008), and Alzheimer's disease (Luchsinger et al., 2002). Additionally, animal models have demonstrated the negative effects of maternal obesity on the brain and peripheral organs of offspring (Williams et al., 2014). We previously reported that mouse pups from obese dams fed with a HFD show peroxidized lipid accumulation in many brain regions, impaired adult neurogenesis in the hippocampus, and deficits in spatial learning performance (Tozuka et al., 2009, 2010). Other animal-model studies have also demonstrated the impairments in conditioned and reversal learning in offspring from HFD-fed dams (Rodriguez et al., 2012; Wu et al., 2013). These lines of evidence suggest that maternal HFD consumption and obesity impact brain development of the offspring, resulting in behavioral impairments in adulthood. Accumulating evidence suggest that maternal HFD consumption leads to the perturbations in serotonergic and dopaminergic systems that regulate brain function and development (Sullivan et al., 2010; Vucetic et al., 2010). Increased levels of inflammatory cytokines (Das, 2001), insulin (Leung and Lao, 2000), and leptin (Lepercq et al., 2002) in obese mothers are considered to influence the development of these neurotransmitter signaling pathways. However, neuronal circuitry and molecular mechanisms underlying the association between maternal HFD consumption and abnormal behavior of the children remain to be elucidated.

\section{Maternal Hormonal Abnormality}

Human and animal-model studies have demonstrated an association between prenatal in utero exposure to testosterone and the deficits in social interaction that was diagnosed as ASD (Baron-Cohen et al., 2005; Hines, 2011; Xu et al., 2013, 2015). Sex steroids such as androgens and estrogens shape the structure of sexual dimorphisms during fetal brain development by their organizing effects (Phoenix et al., 1959; Keefe, 2002; Bonthuis et al., 2010). Intrauterine levels of steroid hormones, including stress and sex steroids, are directly affected by the physical condition of the mother. For example, psychological stress in women correlates with the concentration of testosterone in the blood (Chichinadze and Chichinadze, 2008; Lennartsson et al., 2012). Furthermore, maternal stress during pregnancy is associated with increased risk of ASD in children (Keefe, 2002). Polycystic ovary syndrome (PCOS), characterized by ovarian dysfunction, and polycystic ovarian morphology in women of childbearing age, leads to excessive levels of male hormones, a condition called hyperandrogenism (Franks, 1995; Abbott et al., 2005; Azziz et al., 2005; Goodarzi et al., 2011), and children from PCOS mothers are thought to express more autistic traits (Palomba et al., 2012). Indeed, an animal-model study of maternal hyperandrogenism during pregnancy demonstrated that the offspring exhibit autisticlike behavior from adolescence to adulthood ( $\mathrm{Xu}$ et al., 2015). These lines of evidence suggest that prenatal exposure to testosterone leads to developmental deficits of the brain, resulting in abnormal behavior; however, the underlying mechanism of development of autistic-like behavior remains unclear.

\section{NEUROPSYCHIATRIC DISORDERS AND THEIR DENDRITIC SPINE PATHOLOGIES}

The synapse plays an essential role in brain function. Dendritic spines are postsynaptic structures that receive glutamatergic excitatory input from presynaptic terminals. Dynamic changes in the density and morphology of dendritic spines are associated with the rewiring of neuronal circuits during circuit development (Grutzendler et al., 2002), experience-dependent neuronal plasticity (Trachtenberg et al., 2002), aging (Mostany et al., 2013), and the progression of many neuropsychiatric diseases (Penzes et al., 2011). Human postmortem studies have revealed higher than normal cortical spine density in ASD (Hutsler and Zhang, 2010) and fragile $X$ syndrome (Irwin et al., 2001), which is thought to the result from deficiencies in synaptic pruning during the development of neuronal circuitry. In contrast, spine density was shown to be markedly lower in the postmortem brains of people who had Alzheimer's disease (Tackenberg et al., 2009) or schizophrenia (Selemon and Goldman-Rakic, 1999). Numerous proteins associated with these disorders are involved in the 
regulation of dendritic spine density and morphology (Penzes et al., 2011).

Recent animal studies using in vivo two-photon imaging have suggested that dendritic spine instability results in the aberrant spine density and morphology observed in the brains of mouse models for fragile X syndrome (Cruz-Martín et al., 2010), ASD (Isshiki et al., 2014), and schizophrenia (HayashiTakagi et al., 2014). Dendritic spine instability is thought to be associated with abnormal rewiring of neuronal circuits, a phenomenon also present in neurodegenerative diseases such as Alzheimer's disease (Tsai et al., 2004) and Huntington's disease (Murmu et al., 2013). The dendritic spine instability is assessed by the elevation of formation and elimination rate of spines, and the imbalance between formation and elimination rate leads to subsequent loss or excess of spines. These lines of evidence suggest that dendritic spine instability might be a common pathology to both neurodevelopmental disorders and neurodegenerative diseases. Using a knock-in model mouse that faithfully replicates human symptomatic and pathological features of spinocerebellar ataxia type 1 (SCA1), a late-onset polyglutamine neurodegenerative disease characterized by ataxia, cognitive impairment, and neuronal death, we previously demonstrated that dendritic spine instability becomes evident before pronounced motor incoodination (Hatanaka et al., 2015b). Interestingly, this abnormal synaptic instability is present even during synaptic development. In normal development, dendritic spines are initially unstable, and they become stable in the adult (Grutzendler et al., 2002). Thus, immature dendritic spines during development may more vulnerable to internal and external factors than mature spines. These lines of evidence suggest that a latent developmental abnormality in neuronal circuitry might subsequently lead to neuronal dysfunction and loss in late-onset neurodegenerative diseases, which have otherwise been believed to begin during middle age.

\section{DISTURBANCE IN MATERNAL ENVIRONMENT IMPACTS DENDRITIC SPINE DYNAMICS DURING SYNAPTIC DEVELOPMENT}

Abnormal maternal environments are associated with several neurodevelopmental disorders and neurodegenerative diseases that are characterized by very early synaptic impairment. However, the synaptic mechanism that translates certain maternal environments into future behavioral impairments in offspring is not fully understood. Recently, we reported that maternal HFD consumption and excess testosterone exposure during brain development leads to persistent synaptic instability in mouse offspring (Hatanaka et al., 2015a,b). In this section, we review these two studies and discuss the synaptic mechanism.

\section{Maternal HFD Consumption and Synaptic Impairment in Offspring}

Studies of human and animal models have demonstrated that maternal obesity negatively impacts the neurodevelopment of children (Williams et al., 2014). Mouse pups from obese dams fed with an HFD show peroxidized lipid accumulation in many brain regions, impaired adult neurogenesis in the hippocampus, and deficits in spatial learning, conditioning, and adaptation (Tozuka et al., 2009, 2010; Rodriguez et al., 2012; Wu et al., 2013). However, the synaptic basis for maternal HFD-induced brain dysfunction has remained unclear. Peroxidized lipid accumulation in the brains of the offspring from HFD-fed dams disappears when the offspring are raised on a normal diet after weaning, whereas abnormal progenitor-cell proliferation in the hippocampus and ADHD-like hyperactivity persist into adulthood (Tozuka et al., 2009, 2010). Thus, there may be reversible and irreversible components of the maternal HFDinduced brain impairment found in offspring. To determine the critical period that is most susceptible to maternal HFD consumption for the synaptic impairment, and to establish the association between the oxidative stress in this period (which results from peroxidized lipid accumulation) and impairment in neuronal circuitry development, we analyzed the dynamics and morphology of dendritic protrusions using in vivo two-photon laser-scanning microscopy. This analysis must be conducted in vivo because peripheral organs and non-neuronal cells of the offspring exhibit abnormal metabolic homeostasis that contributes a great deal to synaptic function (Bilbo and Tsang, 2010; Williams et al., 2014).

By analyzing the formation and elimination rate of dendritic spines, we have found that maternal HFD leads to instability of spines in the cerebral cortex of juvenile offspring, even when they are fed with a normal diet after weaning (Hatanaka et al., 2016). This effect persists into adulthood and manifests as a decline in dendritic spine number. When offspring are exposed to maternal HFD exclusively during lactation, their synaptic instability and loss of spines is greater than or equal to that in offspring who are exposed to pre- and postnatal maternal HFD. Antioxidant-treatment during lactation ameliorates the synaptic impairment in the offspring born to HFD-fed dams. These results suggest that maternal obesity causes sustained synaptic impairments in offspring, which may be associated with brain dysfunction in adulthood, and that these impairments may result from oxidative stress caused by peroxidized lipid accumulation during lactation. The maternal metabolic milieu is one of the most important factors that impacts the development of neuronal circuitry and brain function in adulthood. Using in vivo imaging while maintaining the intravital environment, this study provided the first evidence for the synaptic basis of the brain dysfunction in offspring of obese dams.

\section{Prenatal Testosterone Exposure and Abnormal Synaptic Development of Offspring}

ASD is a neurobehavioral syndrome with a heterogeneous phenotype, and its overall prevalence is about 1/100 (Fernell and Gillberg, 2010). Men are more likely to be affected than women, with a 4:1 ratio (Freitag, 2007; Abrahams and Geschwind, 2008). Many lines of evidence from human and animal studies suggest that disturbances in synaptic homeostasis may be a key factor in the development of ASD (Toro et al., 2010; 
Delorme et al., 2013). Although the pathogenesis of ASD is most likely polygenic and potentially epistatic, maternal environmental factors might also interact with genetic factors to increase risk (Gardener et al., 2011; Hallmayer et al., 2011). Epidemiological and animal-model studies suggest that abnormal prenatal exposure to testosterone results in autistic-like behavior in the children (Baron-Cohen et al., 2005; Hines, 2011; Xu et al., 2013). However, the synaptic pathogenesis of abnormal behaviors exhibited by children who are prenatally exposed to excess testosterone remains unexplained. Because neuronal circuitry maturation is accomplished by dendritic spine stabilization and pruning (Grutzendler et al., 2002), we analyzed dendritic spine stabilization during synaptic development in the mouse offspring from PCOS model dams, as a means of estimating deficiency in neuronal circuitry development. Rodent models of PCOS are administered testosterone prenatally and exhibit autistic-like behavior, infertility, obesity, hyperinsulinism, an increased risk of type-II diabetes, cardiovascular disease, and other abnormal reproductive and metabolic functions (Walters et al., 2012). Thus, analyzing dendritic spines in vivo is important because it preserves the contributions that peripheral tissues provide to spine dynamics.

By using in vivo two-photon imaging, we have found that mice exposed prenatally to testosterone show increased rates

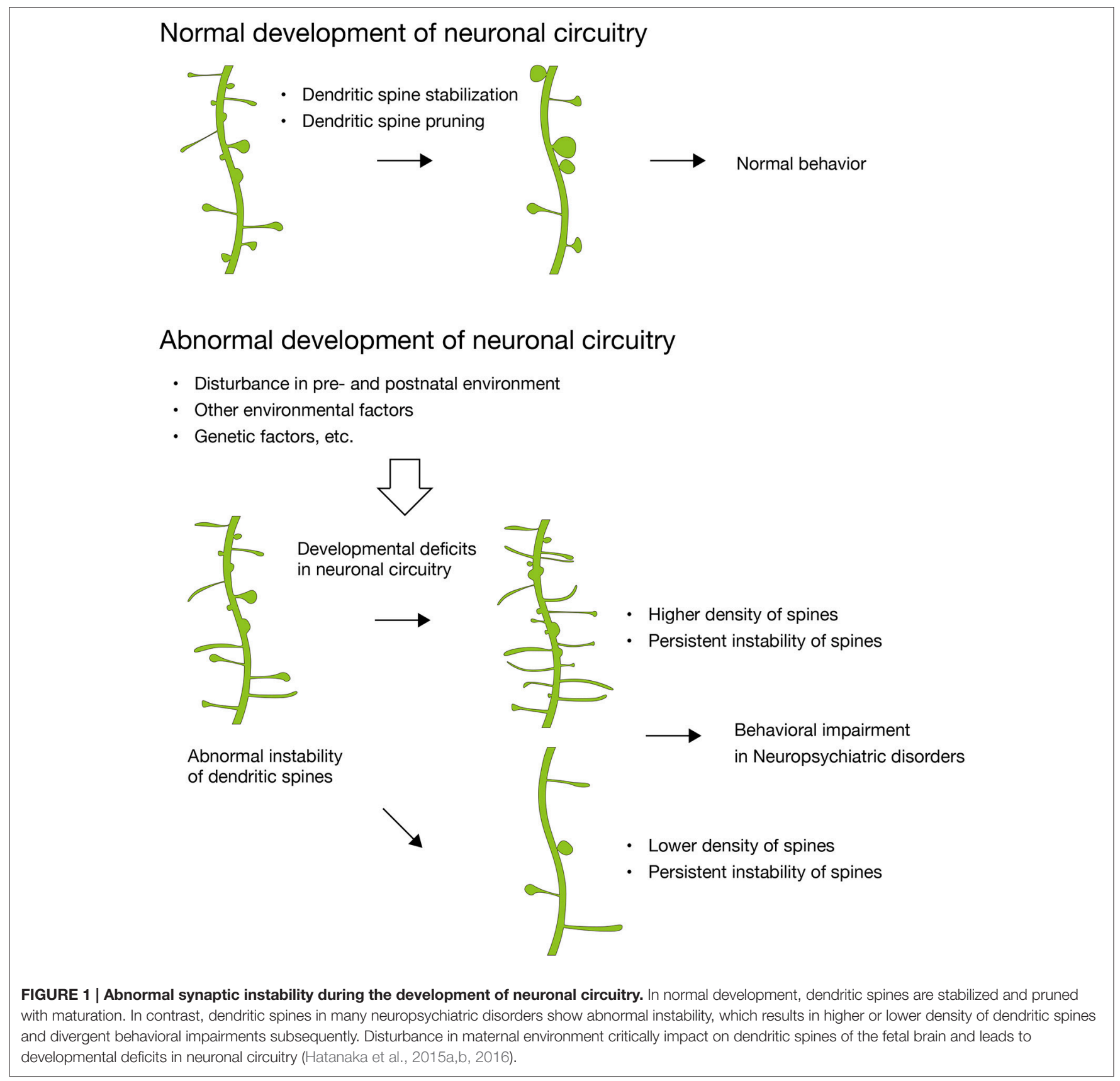


of spine formation and elimination in the frontal cortex at the developmental stage of synapse formation (4-week-old), and that this synaptic instability persists into adulthood (8-week-old) (Hatanaka et al., 2015a). Density of dendritic spines is excessively high, and their morphology is abnormal even when they are in adulthood. This is consistent with post-mortem studies of ASD and fragile X syndrome (Irwin et al., 2001; Hutsler and Zhang, 2010) and in vivo studies of animal models for these conditions (Cruz-Martín et al., 2010; Pan et al., 2010; Jiang et al., 2013; Isshiki et al., 2014). These results suggest that synaptic instability, excess density, and abnormal morphology of dendritic spines are the synaptic basis of subsequent neurodevelopmental deficits in prenatally testosterone-exposed mice that exhibit autisticlike behavior. This study was the first to examine the synaptic basis of neurodevelopmental impairments in offspring who were prenatally exposed to a hyperandrogenic environment.

\section{CONCLUSION}

Recent studies have shown that disturbances in maternal environment are related to neuropsychiatric disorders. However, details regarding the synaptic basis for this phenomenon remain an open question. In this review, we focused on abnormal synaptic instability during synaptic development, which results in excess or loss of synapses in adulthood and in behavioral impairments (Figure 1). We summarized recent discoveries of dendritic spine pathologies in many neurodevelopmental disorders and neurodegenerative diseases that are associated with disturbances in maternal environment, and propose that the abnormal synaptic instability observed during development of neuronal circuitry is a shared pathology

\section{REFERENCES}

Abbott, D. H., Barnett, D. K., Bruns, C. M., and Dumesic, D. A. (2005). Androgen excess fetal programming of female reproduction: a developmental aetiology for polycystic ovary syndrome? Hum. Reprod. Update 11, 357-374. doi: 10.1093/humupd/dmi013

Abrahams, B. S., and Geschwind, D. H. (2008). Advances in autism genetics: on the threshold of a new neurobiology. Nat. Rev. Genet. 9, 341-355. doi: $10.1038 / \mathrm{nrg} 2346$

Allen, K. L., Byrne, S. M., Forbes, D., and Oddy, W. H. (2009). Risk factors for fulland partial-syndrome early adolescent eating disorders: a population-based pregnancy cohort study. J. Am. Acad. Child Adolesc. Psychiatry 48, 800-809. doi: 10.1097/CHI.0b013e3181a8136d

Azziz, R., Marin, C., Hoq, L., Badamgarav, E., and Song, P. (2005). Health care-related economic burden of the polycystic ovary syndrome during the reproductive life span. J. Clin. Endocrinol. Metab. 90, 4650-4658. doi: $10.1210 /$ jc. $2005-0628$

Barlow, B. K., Cory-Slechta, D. A., Richfield, E. K., and Thiruchelvam, M. (2007). The gestational environment and Parkinson's disease: evidence for neurodevelopmental origins of a neurodegenerative disorder. Reprod. Toxicol. 23, 457-470. doi: 10.1016/j.reprotox.2007.01.007

Baron-Cohen, S., Knickmeyer, R. C., and Belmonte, M. K. (2005). Sex differences in the brain: implications for explaining autism. Science 310, 819-823. doi: $10.1126 /$ science. 1115455

Bilbo, S. D., and Tsang, V. (2010). Enduring consequences of maternal obesity for brain inflammation and behavior of offspring. FASEB J. 24, 2104-2115. doi: 10.1096/fj.09-144014 of these neuropsychiatric disorders. The evidence suggests that deficits in synaptic development might be a pathology shared among many neuropsychiatric disorders, including both developmental disorders and late-onset neurodegenerative diseases. Although synaptic instability is a common deficit among these neuropsychiatric disorders, the symptoms and their onset of these different disorders are highly diverse. This can be explained by the neuronal circuitry specificity impaired in each disorder, and the specificity is due to the expression profiles of disease-associated genes. Further studies that combine genetic and environmental risk factors are needed in order to explain the diversity of the neuropsychiatric disorders. Furthermore, additional comprehensive studies demonstrating the relationship between disturbances in maternal environmental, abnormal synaptic instability during neuronal circuitry development, and behavioral impairments in offspring are necessary for further understanding the synaptic mechanisms underlying developmental disorders in the brain.

\section{AUTHOR CONTRIBUTIONS}

$\mathrm{YH}, \mathrm{KW}$, and TK wrote the manuscript.

\section{FUNDING}

This work was supported by Intramural Research Grants for Neurological and Psychiatric Disorders, NCNP [to TK], the Japan Society for the Promotion of Science, Grants-in-Aid for Young Scientists (B) [25871174 and 16K19508 to YH], and a grant from Core Research for Evolutional Science and Technology (CREST), Japan Science and Technology Agency (JST) [to KW].

Bonthuis, P. J., Cox, K. H., Searcy, B. T., Kumar, P., Tobet, S., and Rissman, E. F. (2010). Of mice and rats: key species variations in the sexual differentiation of brain and behavior. Front. Neuroendocrinol. 31:341-358. doi: 10.1016/j.yfrne.2010.05.001

Chichinadze, K., and Chichinadze, N. (2008). Stress-induced increase of testosterone: contributions of social status and sympathetic reactivity. Physiol. Behav. 94, 595-603. doi: 10.1016/j.physbeh.2008. 03.020

Cruz-Martín, A., Crespo, M., and Portera-Cailliau, C. (2010). Delayed stabilization of dendritic spines in fragile $\mathrm{X}$ mice. J. Neurosci. 30, 7793-7803. doi: 10.1523/JNEUROSCI.0577-1 0.2010

Cserjési, R., Moinár, D., Luminet, O., and Lénárdo, L. (2007). Is there any relationship between obesity and mental flexibility in children? Appetite 49, 675-678. doi: 10.1016/j.appet.2007.04.001

Das, U. N. (2001). Is obesity an inflammatory condition? Nutrition 17, 953-966. doi: 10.1016/S0899-9007(01)00672-4

Deierlein, A. L., Siega-Riz, A. M., Adair, L. S., and Herring, A. H. (2011) Effects of pre-pregnancy body mass index and gestational weight gain on infant anthropometric outcomes. J. Pediatr. 158, 221-226. doi: 10.1016/j.jpeds.2010.08.008

Delorme, R., Ey, E., Toro, R., Leboyer, M., Gillberg, C., and Bourgeron, T. (2013). Progress toward treatments for synaptic defects in autism. Nat. Med. 19, 685-694. doi: 10.1038/nm.3193

Favaro, A., Tenconi, E., and Santonastaso, P. (2006). Perinatal factors and the risk of developing anorexia nervosa and bulimia nervosa. Arch. Gen. Psychiatry 63, 82-88. doi: 10.1001/archpsyc.63.1.82 
Fernell, E., and Gillberg, C. (2010). Autism spectrum disorder diagnoses in Stockholm preschoolers. Res. Dev. Disabil. 31, 680-685. doi: 10.1016/j.ridd.2010.01.007

Franks, S. (1995). Polycystic ovary syndrome. N. Engl. J. Med. 333, 853-861. doi: 10.1056/NEJM199509283331307

Freitag, C. M. (2007). The genetics of autistic disorders and its clinical relevance: a review of the literature. Mol. Psychiatry 12, 2-22. doi: 10.1038/sj.mp.40 01896

Gardener, H., Spiegelman, D., and Buka, S. L. (2011). Perinatal and neonatal risk factors for autism: a comprehensive meta-analysis. Pediatrics 128, 344-355. doi: $10.1542 /$ peds.2010-1036

Goodarzi, M. O., Dumesic, D. A., Chazenbalk, G., and Azziz, R. (2011). Polycystic ovary syndrome: etiology, pathogenesis and diagnosis. Nat. Rev. Endocrinol. 7, 219-231. doi: 10.1038/nrendo.2010.217

Grutzendler, J., Kasthuri, N., and Gan, W. B. (2002). Long-term dendritic spine stability in the adult cortex. Nature 420, 812-816. doi: 10.1038/nature01276

Hallmayer, J., Cleveland, S., Torres, A., Phillips, J., Cohen, B., Torigoe, T., et al. (2011). Genetic heritability and shared environmental factors among twin pairs with autism. Arch. Gen. Psychiatry 68, 1095-1102. doi: 10.1001/archgenpsychiatry.2011.76

Hatanaka, Y., Wada, K., and Kabuta, T. (2015a). Abnormal instability, excess density, and aberrant morphology of dendritic spines in prenatally testosterone-exposed mice. Neurochem Int. 85-86, 53-58. doi: 10.1016/j.neuint.2015.04.008

Hatanaka, Y., Wada, K., and Kabuta, T. (2016). Maternal high-fat diet leads to persistent synaptic instability in mouse offspring via oxidative stress during lactation. Neurochem. Int. 97, 99-108. doi: 10.1016/j.neuint.2016. 03.008

Hatanaka, Y., Watase, K., Wada, K., and Nagai, Y. (2015b). Abnormalities in synaptic dynamics during development in a mouse model of spinocerebellar ataxia type 1. Sci. Rep. 5:16102. doi: 10.1038/srep16102

Hayashi-Takagi, A., Araki, Y., Nakamura, M., Vollrath, B., Duron, S. G., Yan, Z., et al. (2014). PAKs inhibitors ameliorate schizophrenia-associated dendritic spine deterioration in vitro and in vivo during late adolescence. Proc. Natl. Acad. Sci. U.S.A. 111, 6461-6466. doi: 10.1073/pnas.1321109111

Hines, M. (2011). Prenatal endocrine influences on sexual orientation and on sexually differentiated childhood behavior. Front. Neuroendocrinol. 32:170-182. doi: 10.1016/j.yfrne.2011.02.006

Huda, S. S., Brodie, L. E., and Sattar, N. (2010). Obesity in pregnancy: prevalence and metabolic consequences. Semin. Fetal Neonatal Med. 15, 70-76. doi: 10.1016/j.siny.2009.09.006

Hutsler, J. J., and Zhang, H. (2010). Increased dendritic spine densities on cortical projection neurons in autism spectrum disorders. Brain Res. 1309, 83-94. doi: 10.1016/j.brainres.2009.09.120

Irwin, S. A., Patel, B., Idupulapati, M., Harris, J. B., Crisostomo, R. A., Larsen, B. P., et al. (2001). Abnormal dendritic spine characteristics in the temporal and visual cortices of patients with fragile- $X$ syndrome: a quantitative examination. Am. J. Med. Genet. 98, 161-167. doi: 10.1002/1096-8628(20010115)98:2<161::AID-AJMG1025>3.0.CO;2-B

Isshiki, M., Tanaka, S., Kuriu, T., Tabuchi, K., Takumi, T., and Okabe, S. (2014). Enhanced synapse remodelling as a common phenotype in mouse models of autism. Nat. Commun. 5:4742. doi: 10.1038/ncomms5742

Jiang, M., Ash, R. T., Baker, S. A., Suter, B., Ferguson, A., Park, J., et al. (2013). Dendritic arborization and spine dynamics are abnormal in the mouse model of MECP2 duplication syndrome. J. Neurosci. 33, 19518-19533. doi: 10.1523/JNEUROSCI.1745-13.2013

Kanagalingam, M. G., Forouhi, N. G., Greer, I. A., and Sattar, N. (2005). Changes in booking body mass index over a decade: retrospective analysis from a Glasgow Maternity Hospital. BJOG 112, 1431-1433. doi: $10.1111 / j .1471-0528.2005 .00685 . x$

Kawai, M., Minabe, Y., Takagai, S., Ogai, M., Matsumoto, H., Mori, N., et al. (2004). Poor maternal care and high maternal body mass index in pregnancy as a risk factor for schizophrenia in offspring. Acta Psychiatr. Scand. 110, 257-263. doi: $10.1111 /$ j.1600-0447.2004.00380.x

Keefe, D. L. (2002). Sex hormones and neural mechanisms. Arch. Sex. Behav. 31, 401-403. doi: 10.1023/A:1019883923346

Kopelman, P. G. (2000). Obesity as a medical problem. Nature 404, 635-643. doi: $10.1038 / 35007508$
Lahiri, D. K., Maloney, B., and Zawia, N. H. (2009). The LEARn model: an epigenetic explanation for idiopathic neurobiological diseases. Mol. Psychiatry 14, 992-1003. doi: $10.1038 / \mathrm{mp} .2009 .82$

Lennartsson, A. K., Kushnir, M. M., Bergquist, J., Billig, H., and Jonsdottir, I. H. (2012). Sex steroid levels temporarily increase in response to acute psychosocial stress in healthy men and women. Int. J. Psychophysiol. 84, 246-253. doi: 10.1016/j.ijpsycho.2012.03.001

Lepercq, J., Hauguel-De Mouzon, S., Timsit, J., and Catalano, P. M. (2002). Fetal macrosomia and maternal weight gain during pregnancy. Diabetes Metab. 28(4 Pt 1), 323-328.

Leung, T. W., and Lao, T. T. (2000). Placental size and large-for-gestational-age infants in women with abnormal glucose tolerance in pregnancy. Diabet. Med. 17, 48-52. doi: 10.1046/j.1464-5491.2000.00226.x

Luchsinger, J. A., Tang, M. X., Shea, S., and Mayeux, R. (2002). Caloric intake and the risk of Alzheimer disease. Arch. Neurol. 59, 1258-1263. doi: 10.1001/archneur.59.8.1258

Mostany, R., Anstey, J. E., Crump, K. L., Maco, B., Knott, G., and Portera-Cailliau, C. (2013). Altered synaptic dynamics during normal brain aging. J. Neurosci. 33, 4094-4104. doi: 10.1523/JNEUROSCI.4825-1 2.2013

Murmu, R. P., Li, W., Holtmaat, A., and Li, J. Y. (2013). Dendritic spine instability leads to progressive neocortical spine loss in a mouse model of Huntington's disease. J. Neurosci. 33, 12997-13009. doi: 10.1523/JNEUROSCI.5284-12.2013

Palomba, S., Marotta, R., Di Cello, A., Russo, T., Falbo, A., Orio, F., et al. (2012). Pervasive developmental disorders in children of hyperandrogenic women with polycystic ovary syndrome: a longitudinal case-control study. Clin. Endocrinol. (Oxf). 77, 898-904. doi: 10.1111/j.1365-2265.2012.04443.x

Pan, F., Aldridge, G. M., Greenough, W. T., and Gan, W. B. (2010). Dendritic spine instability and insensitivity to modulation by sensory experience in a mouse model of fragile X syndrome. Proc. Natl. Acad. Sci. U.S.A. 107, 17768-17773. doi: 10.1073/pnas.1012496107

Patterson, P. H. (2011). Maternal infection and immune involvement in autism. Trends Mol. Med. 17, 389-394. doi: 10.1016/j.molmed.2011.03.001

Penzes, P., Cahill, M. E., Jones, K. A., VanLeeuwen, J. E., and Woolfrey, K. M. (2011). Dendritic spine pathology in neuropsychiatric disorders. Nat. Neurosci. 14, 285-293. doi: 10.1038/nn.2741

Phoenix, C. H., Goy, R. W., Gerall, A. A., and Young, W. C. (1959). Organizing action of prenatally administered testosterone propionate on the tissues mediating mating behavior in the female guinea pig. Endocrinology 65, 369-382. doi: 10.1210/endo-65-3-369

Ray, G. T., Croen, L. A., and Habel, L. A. (2009). Mothers of children diagnosed with attention-deficit/hyperactivity disorder: health conditions and medical care utilization in periods before and after birth of the child. Med. Care 47, 105-114. doi: 10.1097/MLR.0b013e31817e18c0

Rice, F., Jones, I., and Thapar, A. (2007). The impact of gestational stress and prenatal growth on emotional problems in offspring: a review. Acta Psychiatr. Scand. 115, 171-183. doi: 10.1111/j.1600-0447.2006.00895.x

Rodriguez, A. (2010). Maternal pre-pregnancy obesity and risk for inattention and negative emotionality in children. J. Child Psychol. Psychiatry 51, 134-143. doi: $10.1111 / j .1469-7610.2009 .02133 . x$

Rodriguez, A., Miettunen, J., Henriksen, T. B., Olsen, J., Obel, C., Taanila, A., et al. (2008). Maternal adiposity prior to pregnancy is associated with ADHD symptoms in offspring: evidence from three prospective pregnancy cohorts. Int. J. Obes. 32, 550-557. doi: 10.1038/sj.ijo.0803741

Rodriguez, J. S., Rodriguez-Gonzalez, G. L., Reyes-Castro, L. A., Ibanez, C., Ramirez, A., Chavira, R., et al. (2012). Maternal obesity in the rat programs male offspring exploratory, learning and motivation behavior: prevention by dietary intervention pre-gestation or in gestation. Int. J. Dev. Neurosci. 30, 75-81. doi: 10.1016/j.ijdevneu.2011.12.012

Rofey, D. L., Kolko, R. P., Iosif, A. M., Silk, J. S., Bost, J. E., Feng, W., et al. (2009). A longitudinal study of childhood depression and anxiety in relation to weight gain. Child Psychiatry Hum. Dev. 40, 517-526. doi: 10.1007/s10578-0090141-1

Selemon, L. D., and Goldman-Rakic, P. S. (1999). The reduced neuropil hypothesis: a circuit based model of schizophrenia. Biol. Psychiatry 45, 17-25. doi: 10.1016/S0006-3223(98)00281-9

Sullivan, E. L., Grayson, B., Takahashi, D., Robertson, N., Maier, A., Bethea, C. L., et al. (2010). Chronic consumption of a high-fat diet during pregnancy 
causes perturbations in the serotonergic system and increased anxietylike behavior in nonhuman primate offspring. J. Neurosci. 30, 3826-3830. doi: 10.1523/JNEUROSCI.5560-09.2010

Tackenberg, C., Ghori, A., and Brandt, R. (2009). Thin, stubby or mushroom: spine pathology in Alzheimer's disease. Curr. Alzheimer Res. 6, 261-268. doi: 10.2174/156720509788486554

Toro, R., Konyukh, M., Delorme, R., Leblond, C., Chaste, P., Fauchereau, F., et al. (2010). Key role for gene dosage and synaptic homeostasis in autism spectrum disorders. Trends Genet. 26, 363-372. doi: 10.1016/j.tig.2010.05.007

Tozuka, Y., Kumon, M., Wada, E., Onodera, M., Mochizuki, H., and Wada, K. (2010). Maternal obesity impairs hippocampal BDNF production and spatial learning performance in young mouse offspring. Neurochem. Int. 57, 235-247. doi: 10.1016/j.neuint.2010.05.015

Tozuka, Y., Wada, E., and Wada, K. (2009). Diet-induced obesity in female mice leads to peroxidized lipid accumulations and impairment of hippocampal neurogenesis during the early life of their offspring. FASEB J. 23, 1920-1934. doi: 10.1096/fj.08-124784

Trachtenberg, J. T., Chen, B. E., Knott, G. W., Feng, G., Sanes, J. R., Welker, E., et al. (2002). Long-term in vivo imaging of experience-dependent synaptic plasticity in adult cortex. Nature 420, 788-794. doi:10.1038/nature01273

Tsai, J., Grutzendler, J., Duff, K., and Gan, W. B. (2004). Fibrillar amyloid deposition leads to local synaptic abnormalities and breakage of neuronal branches. Nat. Neurosci. 7, 1181-1183. doi: 10.1038/nn1335

Van Lieshout, R. J., Taylor, V. H., and Boyle, M. H. (2011). Pre-pregnancy and pregnancy obesity and neurodevelopmental outcomes in offspring: a systematic review. Obes. Rev. 12, e548-e559. doi: 10.1111/j.1467-789x.2010.00850.x

Vucetic, Z., Kimmel, J., Totoki, K., Hollenbeck, E., and Reyes, T. M. (2010). Maternal high-fat diet alters methylation and gene expression of dopamine and opioid-related genes. Endocrinology 151, 4756-4764. doi: 10.1210/en.2010-0505
Walters, K. A., Allan, C. M., and Handelsman, D. J. (2012). Rodent models for human polycystic ovary syndrome. Biol. Reprod. 86, 149; 1-12. doi: 10.1095/biolreprod.111.097808

Waring, M. E., and Lapane, K. L. (2008). Overweight in children and adolescents in relation to attention-deficit/hyperactivity disorder: results from a national sample. Pediatrics 122, e1-e6. doi: 10.1542/peds.2007-1955

Williams, L., Seki, Y., Vuguin, P. M., and Charron, M. J. (2014). Animal models of in utero exposure to a high fat diet: a review. Biochim. Biophys. Acta 1842, 507-519. doi: 10.1016/j.bbadis.2013.07.006

Wu, T., Deng, S., Li, W. G., Yu, Y., Li, F., and Mao, M. (2013). Maternal obesity caused by overnutrition exposure leads to reversal learning deficits and striatal disturbance in rats. PLoS ONE 8:e78876. doi: 10.1371/journal.pone.0078876

Xu, X. J., Shou, X. J., Li, J., Jia, M. X., Zhang, J. S., Guo, Y., et al. (2013). Mothers of autistic children: lower plasma levels of oxytocin and Arg-vasopressin and a higher level of testosterone. PLOS ONE 8:e74849. doi: 10.1371/journal.pone.0074849

Xu, X. J., Zhang, H. F., Shou, X. J., Li, J., Jing, W. L., Zhou, Y., et al. (2015). Prenatal hyperandrogenic environment induced autistic-like behavior in rat offspring. Physiol. Behav. 138, 13-20. doi: 10.1016/j.physbeh.2014.09.014

Conflict of Interest Statement: The authors declare that the research was conducted in the absence of any commercial or financial relationships that could be construed as a potential conflict of interest.

Copyright (c) 2017 Hatanaka, Kabuta and Wada. This is an open-access article distributed under the terms of the Creative Commons Attribution License (CC BY). The use, distribution or reproduction in other forums is permitted, provided the original author(s) or licensor are credited and that the original publication in this journal is cited, in accordance with accepted academic practice. No use, distribution or reproduction is permitted which does not comply with these terms. 